\title{
Improved NCTF Control Method for a Two-Mass Rotary Positioning Systems
}

\author{
Mohd Fitri Mohd Yakub, B. A. Aminudin \\ Department of Mechanical Precision Engineering, Malaysia-Japan International Institute of Technology (MJIIT), \\ Universiti Teknologi Malaysia International Campus (UTM IC), Kuala Lumpur, Malaysia \\ E-mail:\{fitri@,aminuddin\}@ic.utm.my \\ Received July 28, 2011; revised September 5, 2011; accepted September 12, 2011
}

\begin{abstract}
This paper describes an improvement of the existing nominal characteristic trajectory following (NCTF) as a practical control method for a two-mass rotary point-to-point (PTP) positioning systems. Generally, the NCTF controller consists of a nominal characteristic trajectory (NCT) and a PI compensator. A notch filter is added as a part of the compensator to eliminate the vibration due to the mechanical resonance of the plant. The objective of the NCTF controller is to make the object motion follow the NCT and end at its origin. The NCTF controller is designed based on a simple open-loop experiment of the object. The parameters identification and an exact model of the plant are not necessary for controller design. The performance response of improved NCTF controller is evaluated and discussed based on results of simulation. The effect of the design parameters on the robustness of the NCTF controller to inertia and friction variations is evaluated and compared with conventional PID controller. The results show that the improved NCTF controller has a better positioning performance and is much more robust than the PID controller.
\end{abstract}

Keywords: Improved NCTF, Two-Mass System, Notch Filter, Vibration, Simulation

\section{Introduction}

Precision positioning systems play an important role in industrial engineering applications such as advanced manufacturing systems, semiconductor manufacturing systems and robot systems. Point-to-point (PTP) positioning systems, either of one-mass or multi-mass systems, are used to move an object from one point to another point either in angular or linear position. For example, in application with one-mass system, such as CNC machines, PTP positioning is used to accurately locate the spindle at one or more specific locations to perform operations, such as drilling, reaming, boring, tapping, and punching. In multi-mass systems application, such as in spot-welding robot, which has a long arm for linear system or long shaft in rotary system, PTP positioning is used to locate the manipulator from one location to another.

PTP positioning systems requires high accuracy with a high speed, fast response with no or small overshoot and to be robust to parameter variations and uncertainties. Therefore, the most important requirements in PTP positioning systems are the final accuracy and transition time whereas the transient path is considered as the second important. In PTP applications, parameter varies with the payload and some friction may cause the instability of the performances [1]. In this case, the system performance is expected to be the same or as close as its performance when the system is in normal condition. Thus, robustness is also an important requirement in order to maintain the stability of the positioning systems. A nominal characteristic trajectory following (NCTF) controller as a practical controller for point-to-point positioning systems had been proposed. The NCTF controller consists of two elements namely a nominal characteristic trajectory (NCT) and a PI compensator. It had been reported that the NCTF had a good positioning performance and robustness to parameters variations [2].

However, the NCTF controller that has been proposed is designed based on one-mass rotary system. The positioning systems can only be assumed as one-mass positioning system in the case a rigid coupling is used and there are no flexible elements in between motor and load. On the other hand, the systems should be modeled as multi-mass systems when flexible couplings with low stiffness or other flexible elements are used to connect 
the actuator to other elements.

Some application like in robot industry which have a long arm for linear system or long shaft in rotary system will be considered as two-mass or multi-mass systems. In two-mass systems, low stiffness elements such as couplings or long shaft cause mechanical resonance like vibration between two masses, which may reduce positioning accuracy and gives the unstable performance response of the plant [3]. Therefore, the existing NCTF controller does not work for two-mass rotary positioning systems.

Therefore, enhancement and improvement design of $\mathrm{NCT}$ and a compensator are required to make the NCTF controller suitable for two-mass rotary positioning systems.

In this paper, the improved NCTF controller is expected to control the position and to reduce the vibration that cause by long shaft in between a first and second mass of the system. The performances of the improved NCTF controller is evaluated and compared with the conventional PID controller.

The paper is organized as follows: Section 2 describes the modeling of the systems. Determination of the NCT and its simplified object is explained in Section 3. Next, compensator design using the NCT information and the object response is described in Section 4. Then, the effectiveness of the improved NCTF controller for twomass rotary system is examined through simulations in Section 5. Finally, conclusions are given in the last Section.

\section{Model of the Systems}

Modeling is the construction of physical or mathematical simulation of the real system. It is a process of representing the behavior of the real systems by a collection of mathematical equations [4]. Figure 1 shows the simplified diagram of a rotary positioning system. It consists of mechanical and electromechanical components. Two masses, having the moments of inertia $J_{m}$ and $J_{l}$, are coupled by low stiffness shaft which has the torsion stiffness $K_{s}$ and a damping.

The electrical part of the DC motor is derived by using Kirchoff Voltage Law (KCL):

$$
V_{m}(t)-E_{\text {emf }}(t)=L_{m} \frac{\mathrm{d} i_{m}(t)}{\mathrm{d} t}+R_{m} i_{m}(t)
$$

where $V_{m}(t)$ is input voltage, $E_{\text {em }}(t)$ is electromagnetic field, $L_{m}$ is motor inductance, $R_{m}$ is motor resistance and $i_{m}(t)$ is current. SI units are applicable for all notations. The motor speed is directly proportional to the applied voltage, or precisely:

$$
E_{\text {emf }}(t)=\hat{K}_{b} \dot{\theta}_{m}(t)
$$
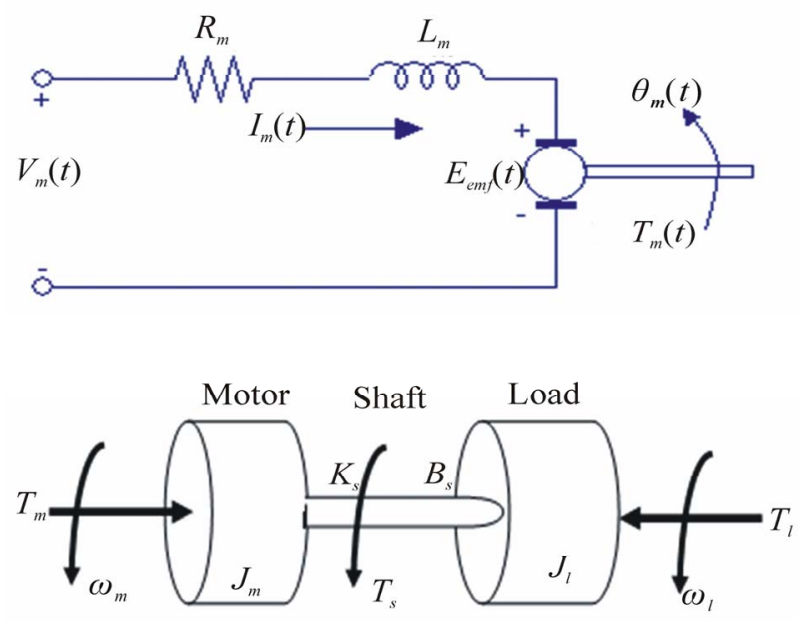

Figure 1. Schematic diagram of two-mass rotary positioning systems.

where $\dot{\theta}_{m}(t)$ is motor angular speed and $\hat{K}_{b}$ is backemf constant. Motor torque characteristic is proportional to the supplied current:

$$
T_{m}(t)=\hat{K}_{t} i_{m}(t)
$$

where $T_{m}(t)$ is motor torque and $\hat{K}_{t}$ is motor-torque constant. Next, modeling on the mechanical parts of the system is done by applying Newton's second law of mo tion to the motor shaft:

$$
J_{m} \frac{\mathrm{d} \omega_{m}(t)}{\mathrm{d} t}=T_{m}(t)-B_{m} \omega_{m}(t)-K_{c} \theta_{m}(t)+K_{c} \theta_{l}(t)
$$

where $J_{m}$ is motor inertia, $B_{m}$ is motor viscous damping and $K_{c}$ is shaft constant. The torque of the load is expressed as follows:

$$
J_{l} \frac{\mathrm{d} \omega_{l}(t)}{\mathrm{d} t}=T_{l}(t)-B_{l} \omega_{l}(t)-K_{c} \theta_{l}(t)+K_{c} \theta_{m}(t)
$$

where $J_{l}$ is inertia of the load, $B_{l}$ is load viscous damping and $T_{l}(t)$ is load torque.

The detailed model of the two-mass rotary positioning systems is used only for making simulation is shown in Figure 2. The parameter of the object used only for making simulation is shown in Table $\mathbf{1}$.

\section{NCTF Control Concept}

The structure of the NCTF control system is shown in Figure 3. The NCTF controller consists of a NCT and a compensator. The NCTF controller works under the following two assumptions [5]:

1) A DC or an AC servo motor is used as an actuator of the object.

2) The reference input, $\theta_{r}$ is constant and $\theta_{r}{ }^{\prime}=0$. 


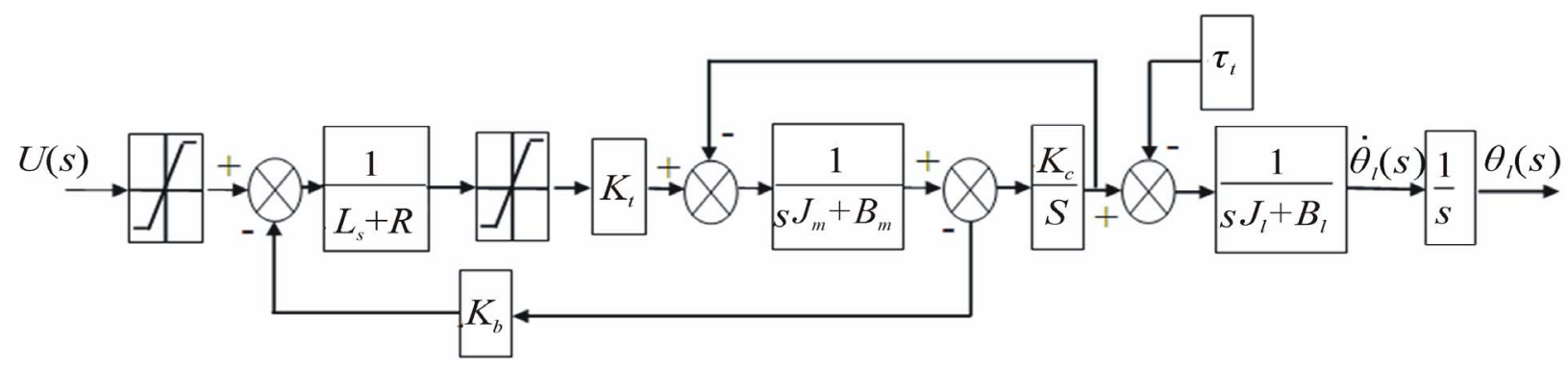

Figure 2. Exact model of the two-mass rotary positioning systems.

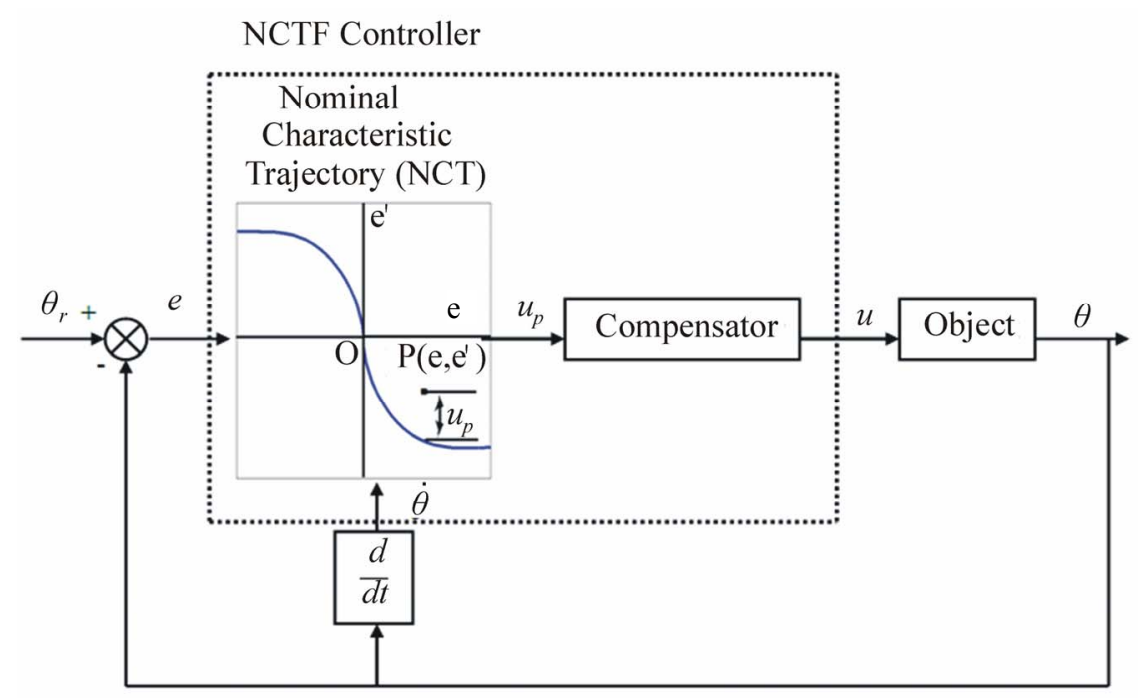

Figure 3. Structure of NCTF control system.

Table 1. Nominal object parameters.

\begin{tabular}{ccc}
\hline Parameter & Value & Unit \\
\hline Motor inertia, $J_{m}$ & $17.16 \mathrm{e}-6$ & $\mathrm{Kgm}^{2}$ \\
Inertia load, $J_{l}$ & $24.17 \mathrm{e}-6$ & $\mathrm{Kgm}^{2}$ \\
Stiffness, $K_{c}$ & 0.039 & $\mathrm{Nm} / \mathrm{rad}$ \\
Motor resistance, $R$ & 5.5 & $\Omega$ \\
Motor inductance, $L$ & $0.85 \mathrm{e}-3$ & $\mathrm{H}$ \\
Torque constant of the motor, $K_{t}$ & 0.041 & $\mathrm{Nm} / \mathrm{A}$ \\
Motor voltage constant, $K_{b}$ & 0.041 & $\mathrm{Vs} / \mathrm{rad}$ \\
Frictional torque, $T_{f}$ & 0.0027 & $\mathrm{Nm}$ \\
Motor viscous friction, $B_{m}$ & $8.35 \mathrm{e}-6$ & $\mathrm{Nms} / \mathrm{rad}$ \\
Load viscous friction, $B_{l}$ & $8.35 \mathrm{e}-6$ & $\mathrm{Nms} / \mathrm{rad}$ \\
\hline
\end{tabular}

The objective of the NCTF controller is to make the object motion follow the NCT and end at the origin of the phase plane $\left(e, e^{\prime}\right)$. Signal $u_{p}$ shown in Figure 3, represents the difference between the actual error rate $e^{\prime}$ and that of the NCT. The value of $u_{p}$ is zero if the object motion perfectly follows the NCT. The compensator is used to control the object so that the value of $u_{p}$, which is used as an input to the compensator, is zero.

Figure 4 shows an example of object motion con- trolled by the NCTF controller. The object motion comprises two phases: one is the reaching phase and the other, the following phase. In the reaching phase, the compensator forces the object motion to reach the NCT as fast as possible. In the following phase, the compensator controls the object motion to follow the NCT and end at the origin. The object motion stops at the origin, which represents the end of the positioning motion. Thus, the NCT governs the positioning response performance.

The NCTF controller consists of NCT, which is constructed based on a simple open-loop experiment of the object, and PI compensator, which is designed based on the obtained NCT. Therefore, the design of NCTF controller can be described by the following steps [6]:

1) The object is driven with an open loop stepwise input and its displacement and velocity responses are measured.

2) Construct the NCT by using the object responses obtained during the deceleration process. Since the NCT is constructed based on the actual responses of the object, it contains nonlinear characteristics such as friction and saturation. The NCTF controller is expected to avoid impertinent behavior by using the NCT. 


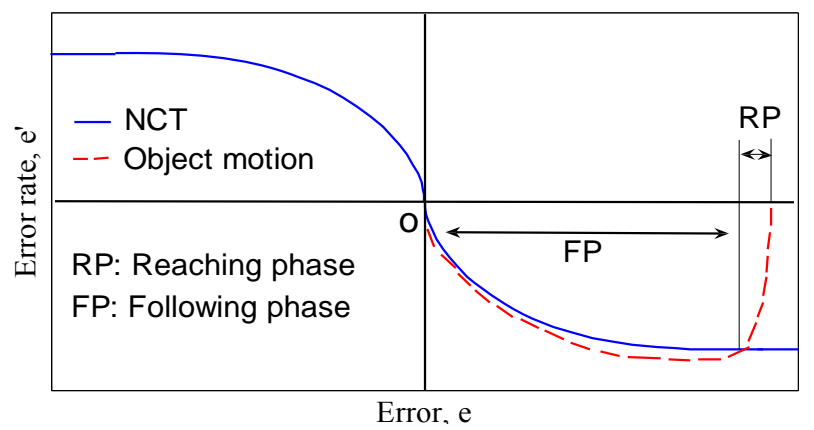

Figure 4. NCT and object motion.

3) Design the compensator based on the NCT information. The NCT includes information of the actual object parameters. Therefore, the compensator can be designed by using only the NCT information.

Due to the fact that the NCT and the compensator are constructed from a simple open-loop experiment of the object, the exact model including the friction characterristic and the conscious identification task of the object parameters are not required to design the NCTF controller. The controller adjustment is easy and the aims of its control parameters are simple and clear.

\section{Controller Design for Two-Mass Systems}

\subsection{NCT Determination}

In order to determine the NCT, the actuator is driven with stepwise inputs, and the load displacement and load velocity responses of the object are measured. Figure 5 shows the stepwise input, load displacement and load velocity responses of the object. In this case, the object vibrates due to its mechanical resonance [7]. In order to eliminate the influence of the vibration on the NCT, the object responses must be averaged. Figure 6 shows the averaged object responses.

The parameter of the object used only for making simulation is shown in Table 1. In Figure 6, moving averaged filter is used because of its simplicity [7]. As the name implies, the moving averaged filter operates by averaging a number of points from the object responses to produce each point in the averaged responses. The averaged velocity and displacement responses are used to determine the NCT. Since the main problem of the PTP motion control is to stop an object at a certain position, a deceleration process (curve in area $A$ of Figure 7) is used. Variable $h$ in Figure 7 is the maximum velocity, which depends on the input step height. From the curve in area $A$ and $h$ in Figure 7(a), the NCT in Figure 7(b) is determined.

There are two important parameters in the NCT as shown in Figure 7(b): the maximum error rate indicated

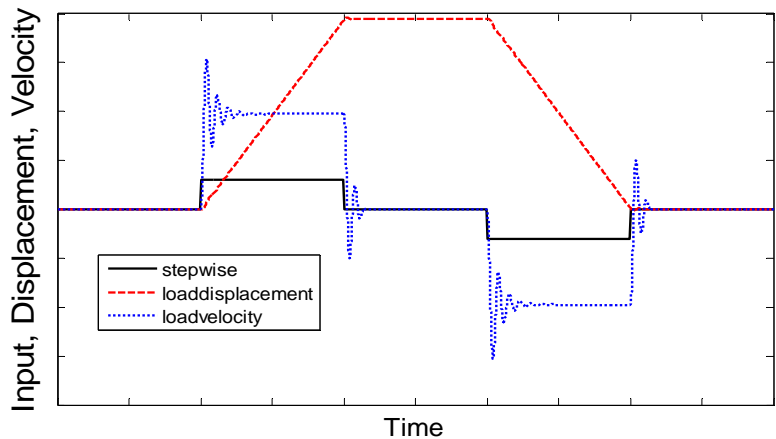

Figure 5. Stepwise input and actual object responses.

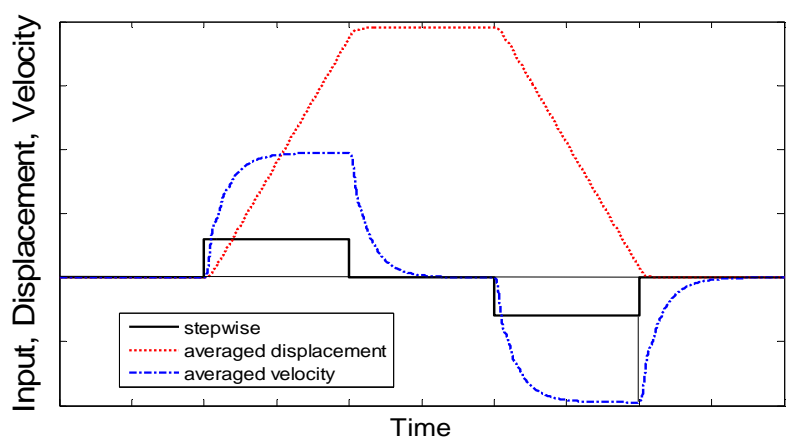

Figure 6. Stepwise input and averaged object responses.

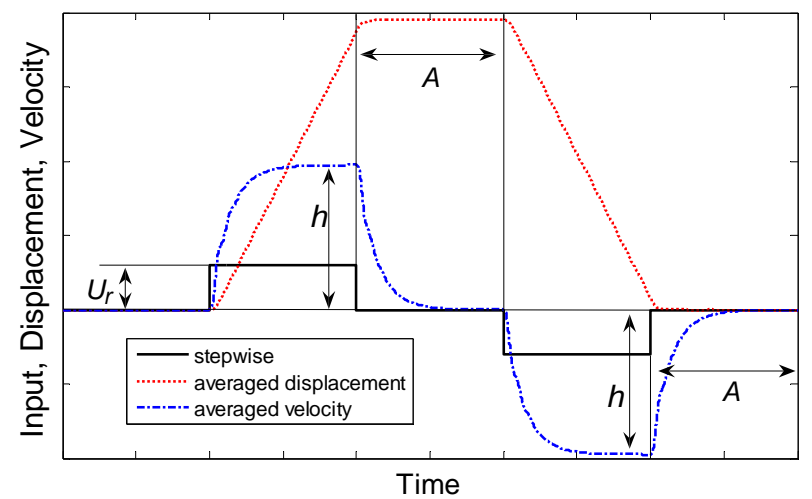

(a)

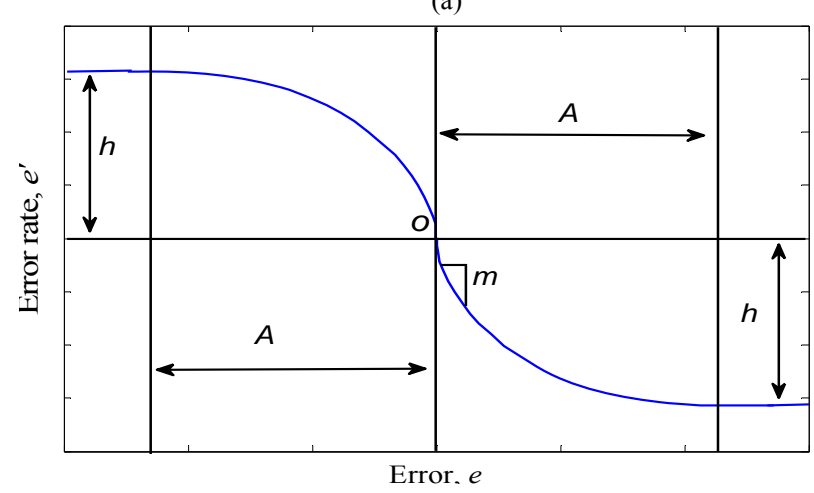

(b)

Figure 7. NCT determination: (a) Stepwise input and averaged object responses; (b) Nominal characteristic trajectory. 
by $h$, and the inclination of the NCT near the origin indicated by $m$.

As discussed in the following section, these parameters are related to the dynamic parameters of the object. Therefore, the parameters are used to design the compensator.

An exact modeling including friction and conscious identification processes are not required in the NCTF controller design. The compensator is derived from the parameter $m$ and $h$ of the NCT. Since the DC motor is used as the actuator, the simplified object can be presented as a following fourth-order system:

$$
G_{o}(s)=\frac{\theta_{l}(s)}{U(s)}=K \frac{\alpha_{2}}{s\left(s+\alpha_{2}\right)} \frac{\omega_{f}^{2}}{s^{2}+2 \zeta_{f} \omega_{f} s+\omega_{f}^{2}}
$$

where $\theta_{l}(s)$ represents the load displacement of the object in $\operatorname{rad}, U(s)$, the input to the actuator in volt and $K, \zeta$, $\alpha_{2}$ and $\omega_{f}$ are simplified object parameters to be determined. The NCT is determined based on the averaged object response which is does not include the vibration. So, it can be assumed that the averaged object response is a response to the stepwise inputs of the averaged object model as follows:

$$
\frac{\theta_{a v}(s)}{U(s)}=K \frac{\alpha_{2}}{s\left(s+\alpha_{2}\right)}
$$

where $\theta_{a v}(s)$ is the averaged load displacement, $U(s)$, input to the actuator and $K$ and $\alpha_{2}$ are simplified object parameters that related to the NCT information. The relations between simplified parameters $K$ and $\alpha_{2}$ and the NCT information are [6]:

$$
\begin{aligned}
& \alpha_{2}=-m \\
& K=-\frac{h}{u_{r}}
\end{aligned}
$$

where $m$ is the inclination of the NCT near the origin, $h$, is maximum error rate of $\mathrm{NCT}$ and $u_{r}$ is a voltage input to the plant.

\subsection{Compensator Design}

The following PI and notch filter (NF) compensator is pro- posed for two-mass systems:

$$
G_{c}(s)=\left(\frac{K_{p} s+K_{i}}{s}\right)\left(\frac{K_{d c}\left(s^{2}+2 \zeta_{f} \omega_{f} s+\omega_{f}^{2}\right)}{\left(s^{2}+2 \zeta_{o} \omega_{o} s+\omega_{o}^{2}\right)}\right)
$$

The PI compensator is adopted for its simplicity to forces the object motion to reach the NCT as fast as possible and control the object motion to follow the NCT and end at the origin.

In a two-mass system, the mechanical couplings between the motor, load, and sensor are not perfectly rigid, but instead, act like springs. Here, the motor response may cause overshoot or even oscillation at the resonance frequency resulting in a longer settling time. The most effective way to deal with this torsional resonance is by using an anti-resonance NF.

According to standard frequency analysis, resonance is characterized by a pair of poles in the complex frequency plane. The imaginary component indicates the resonant frequency, while the real component determines the damping level. The larger the magnitude of the real part, the greater the damping will be [8]. Figure 8 shows where the poles and zeros of the system are located on the s-plane. Figure 8(a) shows the root locus of the system without the controller, which results in unstable responses. In Figure 8(b), the poles marked $A$ are the ones due to the mechanical resonance. These are cancelled by the complex zeros marked by $B$. Although it is assumed that the NF completely cancels the resonance poles, perfect cancellation is not required. As long as the NF zeros

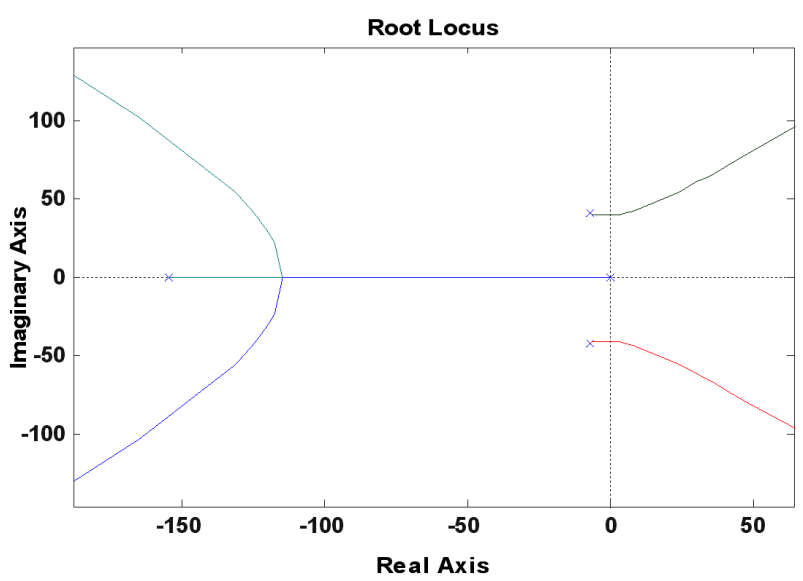

(a)

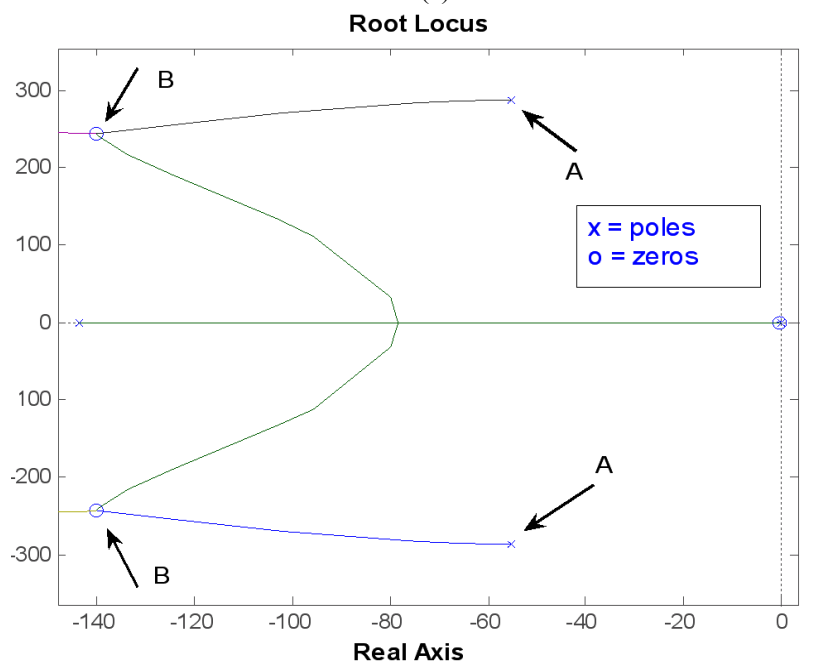

(b)

Figure 8. System responses: (a) Root locus of the system; (b) Pole and Zero cancellation of the NF. 
are close enough to the original plant poles, they can adequately reduce the effect of the later, thereby improve the system response.

Figure 9 shows the effect of the NF to the system in time domain.

Figure 10 shows the block diagram of the continuous closed loop NCTF control system with the simplified object model near the NCT origin where the NCT is linear and has an inclination $\alpha_{2}=-m$. The proportional and integral compensator gains are calculated [9].

The signal $u_{p}$ near the NCT origin in Figure 10 can be expressed as the following equation:

$$
u_{p}=\dot{e}+\alpha_{2} e=\alpha_{2} e-\dot{\theta}_{l}
$$

A higher $\omega_{n}$ and a larger $\zeta$ are preferable in the compensator design. The selection of $\omega_{n}$ and $\zeta$ are chosen to have $40 \%$ of the values of $\zeta$ practical, so that the margin safety of design is $60 \%$ [9]. During the design parameter selection, the designer may be tempted to use large values of $\omega_{n}$ and $\zeta$ in order to improve the performance.
However they are constrained by the sampling time of the systems which may lead the system to instability.

\section{Simulation Results}

Conventional PID controllers were designed based on a Ziegler Nichols and Tyres Luyben closed loop method, using proportional control only. The proportional gain is increased until a sustained oscillation output occur which giving the sustained oscillation, $K_{u}$, and the oscillation period, $T_{u}$ are recorded. The tuning parameter can be found in Table 2 [10]. The detailed model of the object used only for making simulations is shown in Figure 2. In the detailed model of the object, friction and saturation are taken into consideration [11]. The significance of this research lies in the fact that a simple and easy controller can be designed for high precision positioning system which is very practical. By improving the NCTF controller, it will be more reliable and practical for realizing high precision positioning systems for two-mass

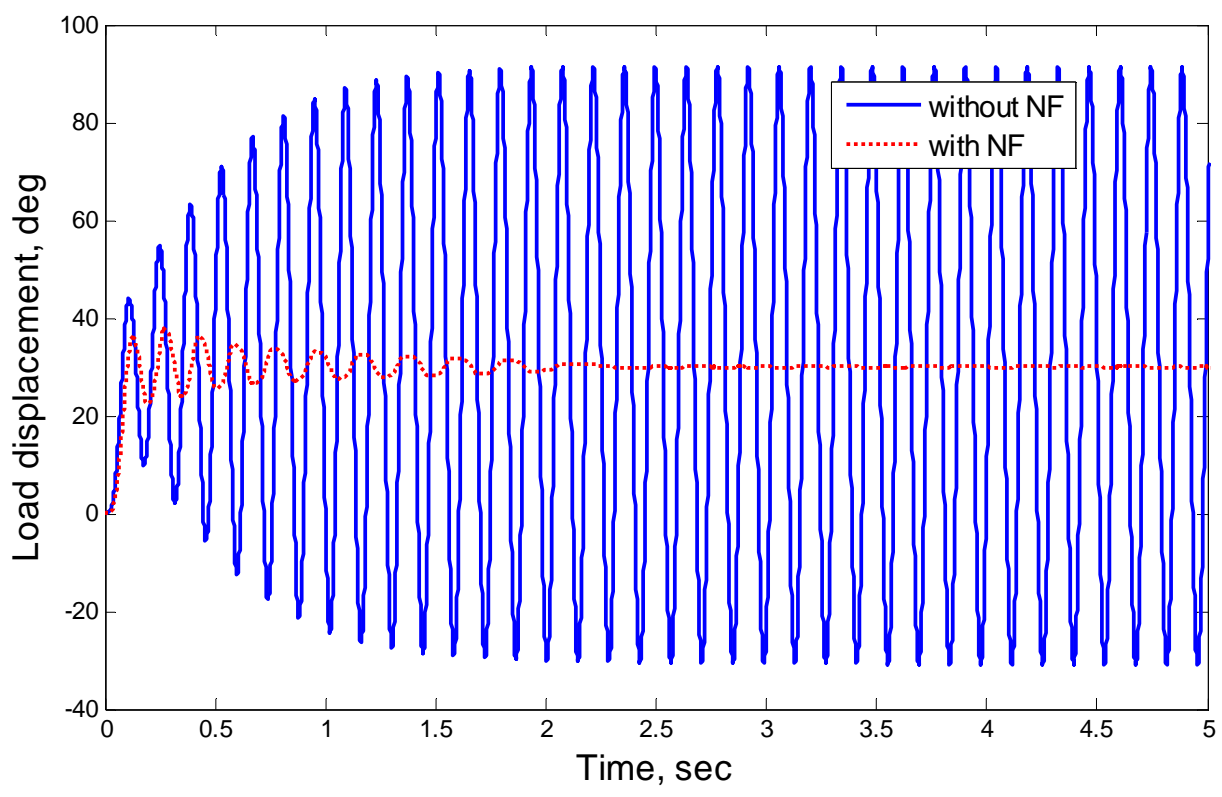

Figure 9. Effect of the NF to the system in time domain.

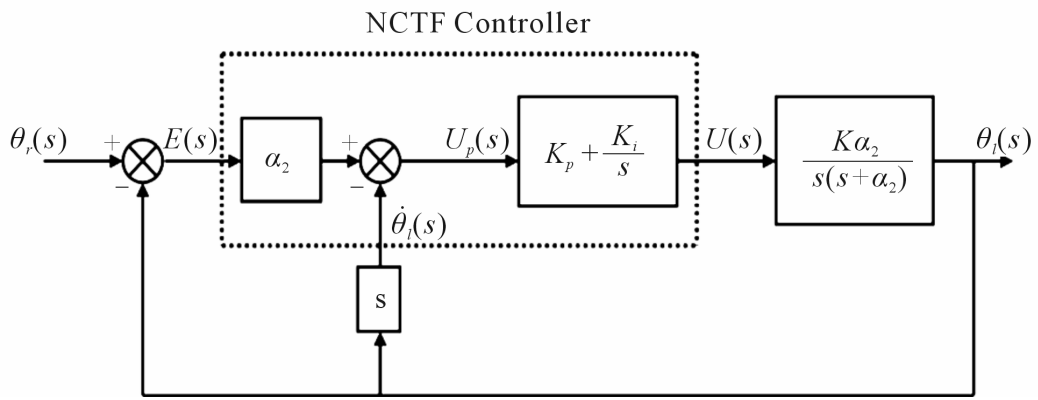

Figure 10. Simplified NCTF control system at small error $e$. 
Table 2. Controller parameters.

\begin{tabular}{lccccccc}
\hline Controller & $\boldsymbol{K}_{\boldsymbol{p}}$ & $\boldsymbol{K}_{\boldsymbol{i}}$ & $\boldsymbol{K}_{\boldsymbol{d}}$ & $\varsigma_{f}$ & $\boldsymbol{\omega}_{f}$ & $\boldsymbol{S}_{\boldsymbol{o}}$ & $\boldsymbol{\omega}_{\boldsymbol{o}}$ \\
\hline Improved NCTF & $4.79 \mathrm{e}^{-1}$ & $2.65 \mathrm{e}^{-1}$ & - & 0.7 & 40 & 0.9 & 60 \\
Ziegler Nichols PID & 78.696 & 4918.5 & 0.31478 & - & - & - & - \\
Tyres Luyben PID & 59.618 & 846.85 & 0.30282 & - & - & - & - \\
\hline
\end{tabular}

positioning systems compared with conventional PID in term of controller performances.

The stepwise input is applied to the object. Its load displacement and load velocity responses due to stepwise input are shown in Figure 5. The input to the actuator $u_{r}$ is $12 \mathrm{~V}$. The object response vibrates with a vibrating frequency $\omega_{f d}$ of $40 \mathrm{~Hz}$. The object responses are averaged by using the moving average filter as shown in Figure 7(a). By using the averaged responses, the NCT is determined as shown in Figure 7(b). In Figure 7(b), the inclination of the NCT near the origin, $m$ is 61.6 and the maximum error rate indicate by $h$ is $156.8 \mathrm{rad} / \mathrm{s}$. Selection of NF parameters are based on Routh-Hurwitz stability criterion. In order to obtain an always stable continuous closed-loop system, the following constraint needs to be satisfied.

$$
2 \zeta_{o} \omega_{o} \geq-\alpha_{2}
$$

In order to evaluate the effectiveness of improved NCTF controller designed for a two-mass system, the controller is compared with PID controllers, which are tuned using Ziegler-Nichols and Tyres-Luyben methods.

The PI compensator parameters are calculated from the simplified object parameters $\left(K\right.$ and $\left.\alpha_{2}\right)$ and the design parameters $\left(\omega_{n}\right.$ and $\left.\zeta\right)$. Table 2 shows the parameters of the compensator of the improved NCTF controller and PID controller.

For simulation purpose, the exact model of the object and its nominal parameters taken from plant identification as described in [12]. In order to evaluate the robustness of the improved NCTF control system, the simulations were conducted in three conditions: with normal load, with increasing the load inertia, and with increasing the friction as shown in Table 3. All process within 10 second simulation time.

Figure 11 shows step responses to 30 and 90 deg step input when the improved NCTF controller is used to control a normal object. The positioning performance is evaluated based on percentage of overshoot, settling time and positioning accuracy. Figure 12 shows step responses to 30 and 90 deg step input to control the object

Table 3. Object parameter comparison.

\begin{tabular}{ccc}
\hline Object & Inertia & Friction \\
\hline Normal load & $J_{l}=14.17 \times 10^{-6} \mathrm{~kg} \cdot \mathrm{m}^{2}$ & $\tau_{\text {fmax }}=0.0027$ \\
\hline \multirow{2}{*}{ Increased inertia load } & $2 \times J_{l}$ & $\tau_{\text {fmax }}$ \\
& $5 \times J_{l}$ & \\
\hline \multirow{2}{*}{ Increased friction object } & $10 \times J_{l}$ & $2 \times \tau_{\text {fmax }}$ \\
& $J_{l}$ & $10 \times \tau_{\text {fmax }}$ \\
\hline
\end{tabular}

Table 4. Positioning performance comparison, increased object inertia.

\begin{tabular}{|c|c|c|c|c|c|}
\hline \multicolumn{3}{|c|}{ Controller } & $\begin{array}{c}\text { OS } \\
(\%)\end{array}$ & $\begin{array}{c}\text { Ts } \\
\text { (sec) }\end{array}$ & $\begin{array}{c}\text { ess } \\
\text { (deg) }\end{array}$ \\
\hline \multirow{2}{*}{$J_{l}$} & $\begin{array}{c}30 \\
\text { deg } \\
\text { input }\end{array}$ & $\begin{array}{c}\text { Z-N } \\
\text { T-L } \\
\text { NCTF }\end{array}$ & $\begin{array}{c}38.3 \\
17.4 \\
0\end{array}$ & $\begin{array}{l}1.246 \\
1.485 \\
0.761\end{array}$ & $\begin{array}{l}1.16 \\
0.01 \\
0.08\end{array}$ \\
\hline & $\begin{array}{c}90 \\
\text { deg } \\
\text { input }\end{array}$ & $\begin{array}{c}\text { Z-N } \\
\text { T-L } \\
\text { NCTF }\end{array}$ & $\begin{array}{l}47.6 \\
19.6 \\
6.4\end{array}$ & $\begin{array}{l}1.023 \\
1.135 \\
0.335\end{array}$ & $\begin{array}{c}1.15 \\
0 \\
0\end{array}$ \\
\hline \multirow{2}{*}{$2 \times J_{l}$} & $\begin{array}{c}30 \\
\text { deg } \\
\text { input }\end{array}$ & $\begin{array}{c}\text { Z-N } \\
\text { T-L } \\
\text { NCTF }\end{array}$ & $\begin{array}{c}83.2 \\
18.7 \\
6.9\end{array}$ & $\begin{array}{c}1.46 \\
1.396 \\
0.91\end{array}$ & $\begin{array}{c}0.94 \\
0.2 \\
0.07\end{array}$ \\
\hline & $\begin{array}{c}90 \\
\text { deg } \\
\text { input }\end{array}$ & $\begin{array}{c}\text { Z-N } \\
\text { T-L } \\
\text { NCTF }\end{array}$ & $\begin{array}{c}83.7 \\
22 \\
7.2\end{array}$ & $\begin{array}{l}1.067 \\
1.118 \\
0.44\end{array}$ & $\begin{array}{l}0.92 \\
0.82 \\
0.45\end{array}$ \\
\hline \multirow{2}{*}{$5 \times J_{l}$} & $\begin{array}{c}30 \\
\text { deg } \\
\text { input }\end{array}$ & $\begin{array}{c}\text { Z-N } \\
\text { T-L } \\
\text { NCTF }\end{array}$ & $\begin{array}{l}31.2 \\
33.9\end{array}$ & $\begin{array}{c}\text { unstable } \\
1.144 \\
0.89\end{array}$ & $\begin{array}{l}0.45 \\
0.14\end{array}$ \\
\hline & $\begin{array}{c}90 \\
\text { deg } \\
\text { input }\end{array}$ & $\begin{array}{c}\text { Z-N } \\
\text { T-L } \\
\text { NCTF }\end{array}$ & $\begin{array}{c}36.6 \\
8.5\end{array}$ & $\begin{array}{c}\text { unstable } \\
1.111 \\
0.765\end{array}$ & $\begin{array}{l}0.81 \\
0.52\end{array}$ \\
\hline
\end{tabular}



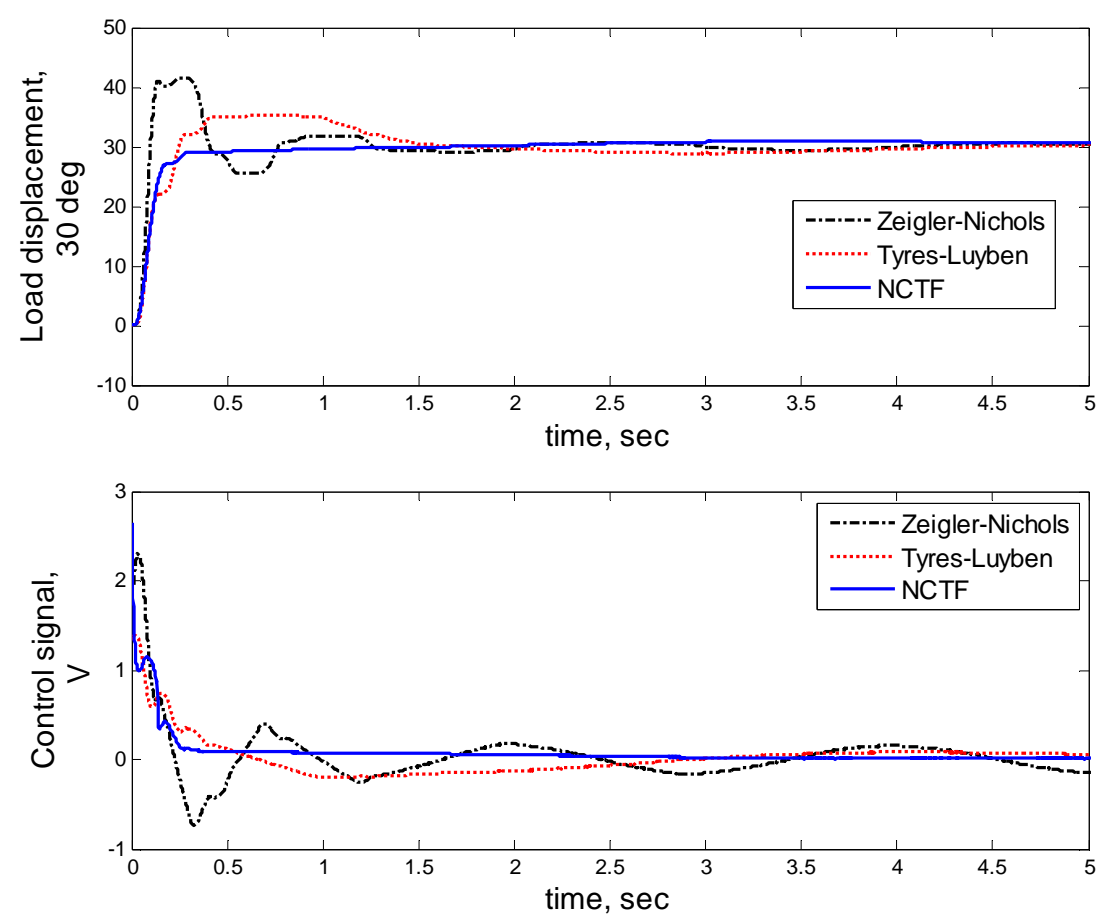

(a)
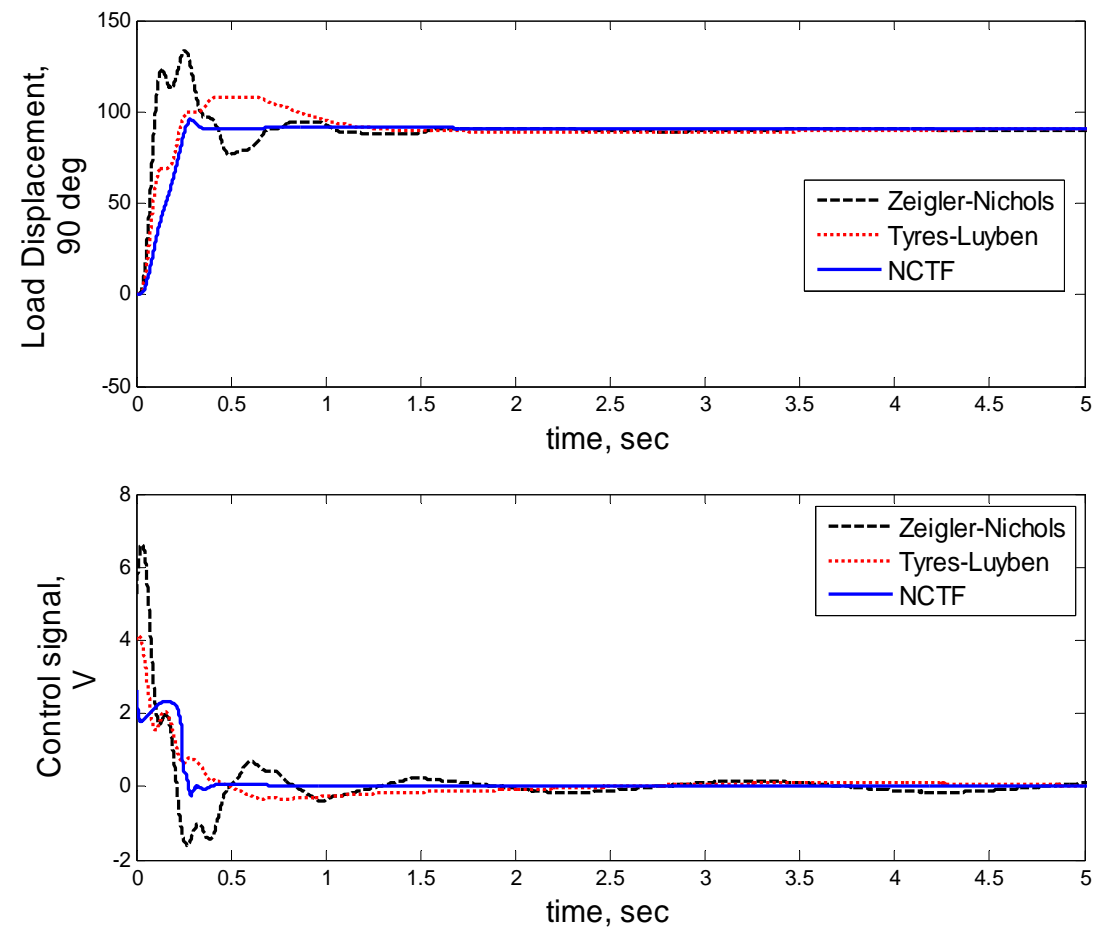

(b)

Figure 11. Step response comparisons, nominal object: (a) Step response 30 deg; (b) Step response 90 deg.

with the increase in the load twice of nominal object $(2 \times$ $\left.J_{l}\right)$.

Figure 13 shows step responses to 30 and 90 deg step input to control the object with the load increase five time of the normal object $\left(5 \times J_{l}\right)$. The positioning per- formances based on simulations for normal and increased object inertia are presented in Table 4. Figures 14 and 15 show step responses to 30 and $90 \mathrm{deg}$ step input to control the object with the increase in twice and ten times $\left(2 \times \tau_{f \max }\right.$ and $\left.10 \times \tau_{f \max }\right)$ the maximum friction 

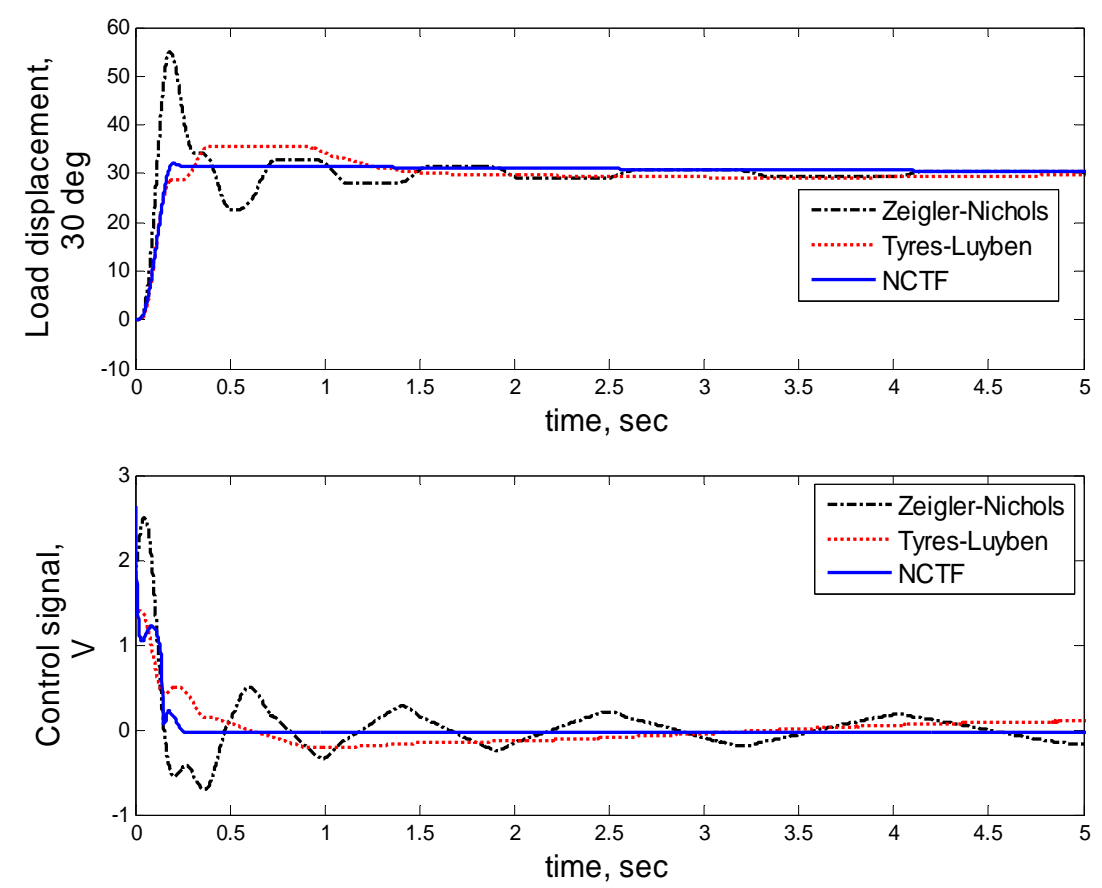

(a)
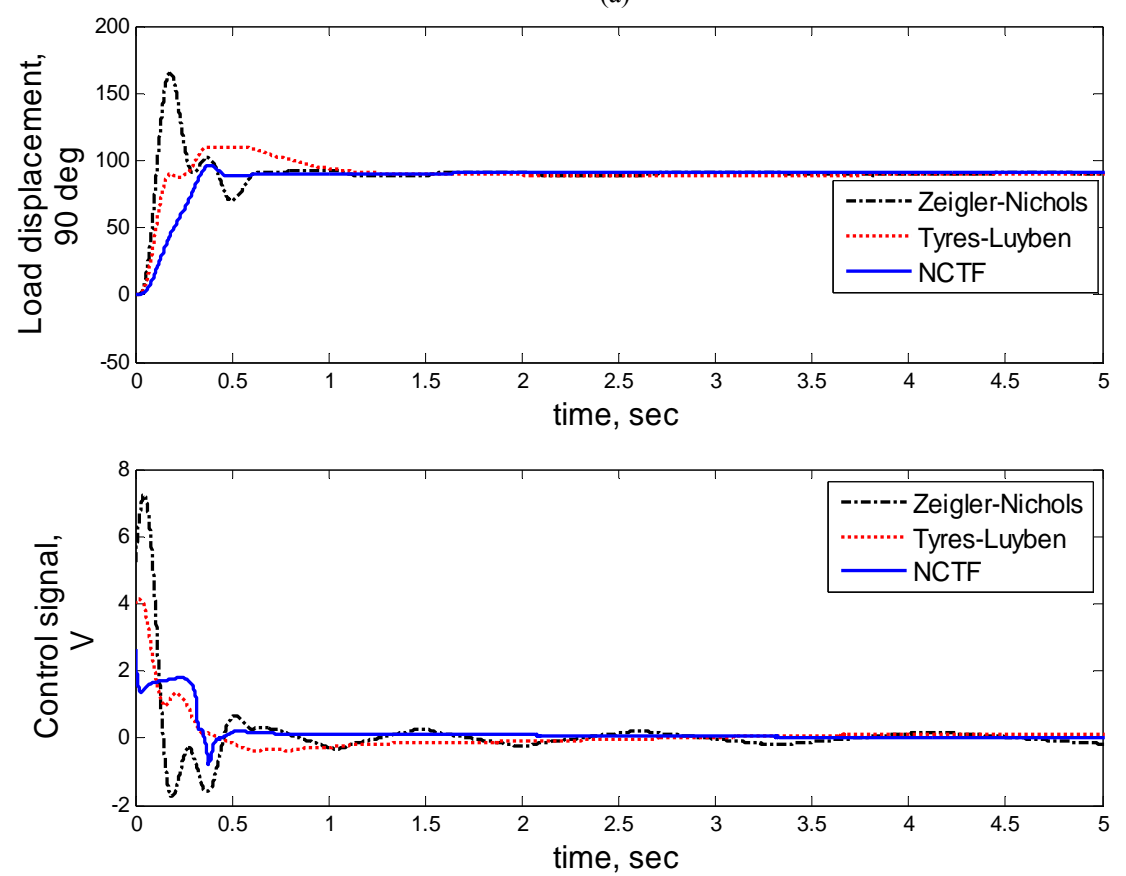

(b)

Figure 12. Step response comparison, increased inertia object $\left(2 \times J_{l}\right):(a)$ Step response 30 deg, (b) Step response 90 deg.

factor. The positioning performances based on simulations for normal and increased friction factor are presented in Table 5. Figure 16 shows the object motion follows the NCT for $30 \mathrm{deg}$ step input.

In nominal object, the improved NCTF controller gives the smallest percentage of overshoot and has the fastest settling time compared with both PID controllers.
The improved NCTF controller gives a better positioning accuracy than PID designed with Ziegler-Nichols but less accuracy than Tyres-Luyben PID controller. With increased object inertia, improved NCTF controller still gives the fastest settling time and smaller overshoot than PID controllers. Improved NCTF controller also has a stable response, even if the control signal is saturated, 

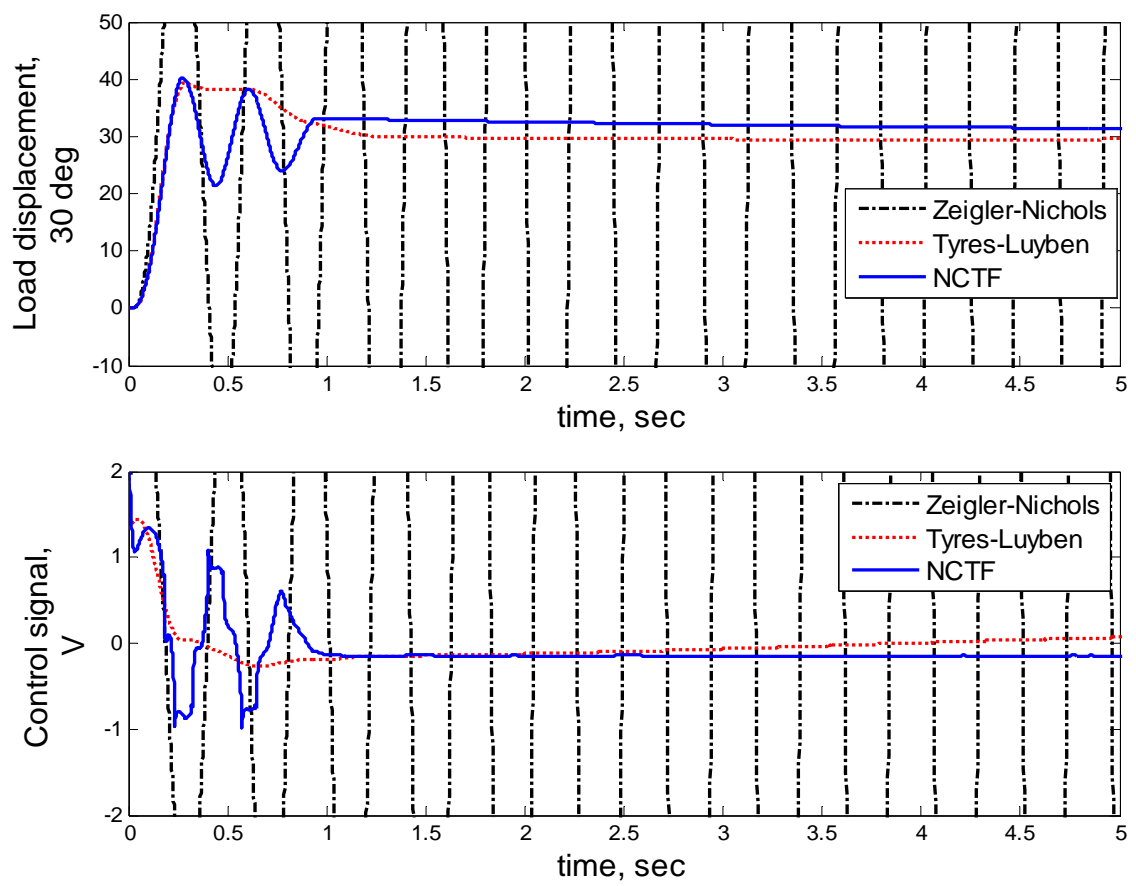

(a)
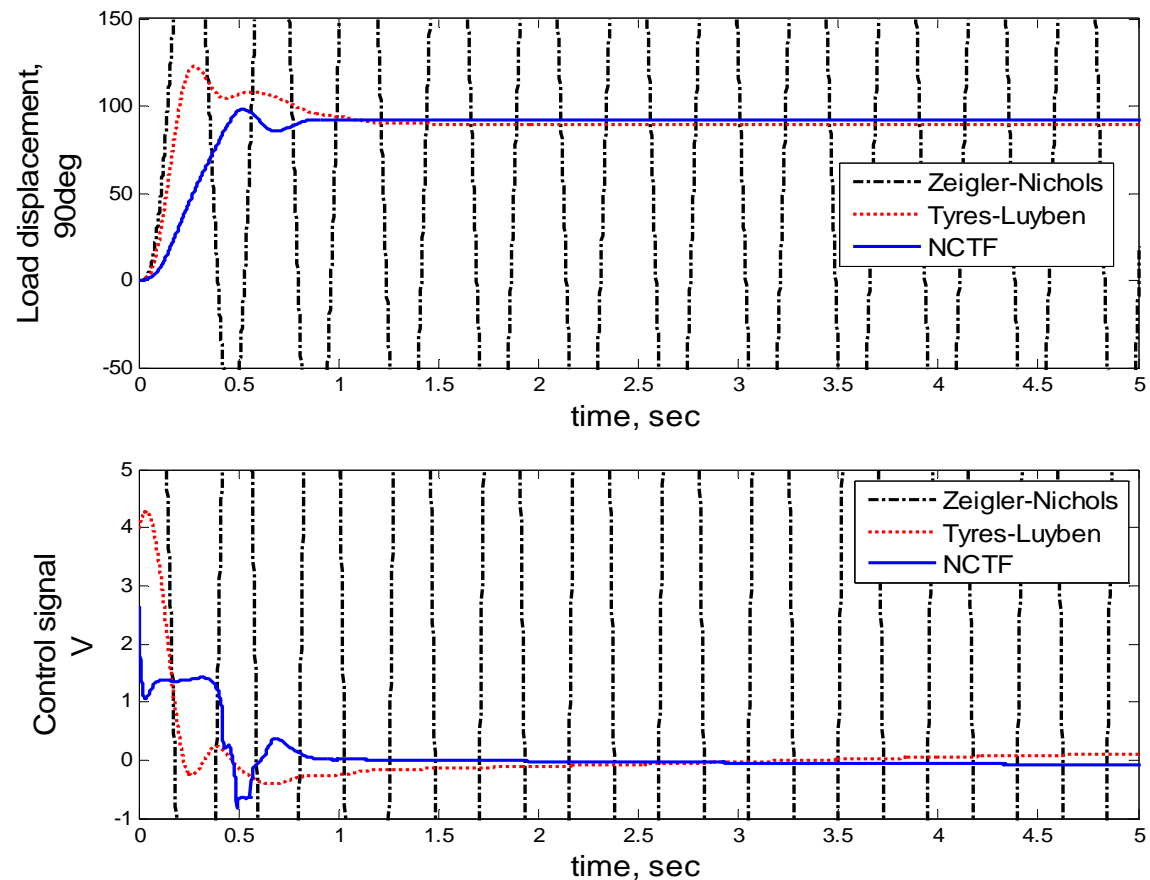

(b)

Figure 13. Step response comparison, increased inertia object $\left(5 \times J_{l}\right):($ a) Step response $30 \mathrm{deg}$, (b) Step response 90 deg.

meanwhile the use of PID controllers result in unstable responses. So, improved NCTF controller is much more robust to inertia variation compared with PID controllers. With increased friction, the improved NCTF controller gives smallest percentage of overshoot as well as the fastest settling time compared with PID controllers. The positioning accuracy does not change significantly due to friction variation and saturation of the control signal. Hence, it is proven by simulations that the improved NCTF controller is much more robust to friction variation compared to PID controllers, even if the saturation of the controller signal occurs. 

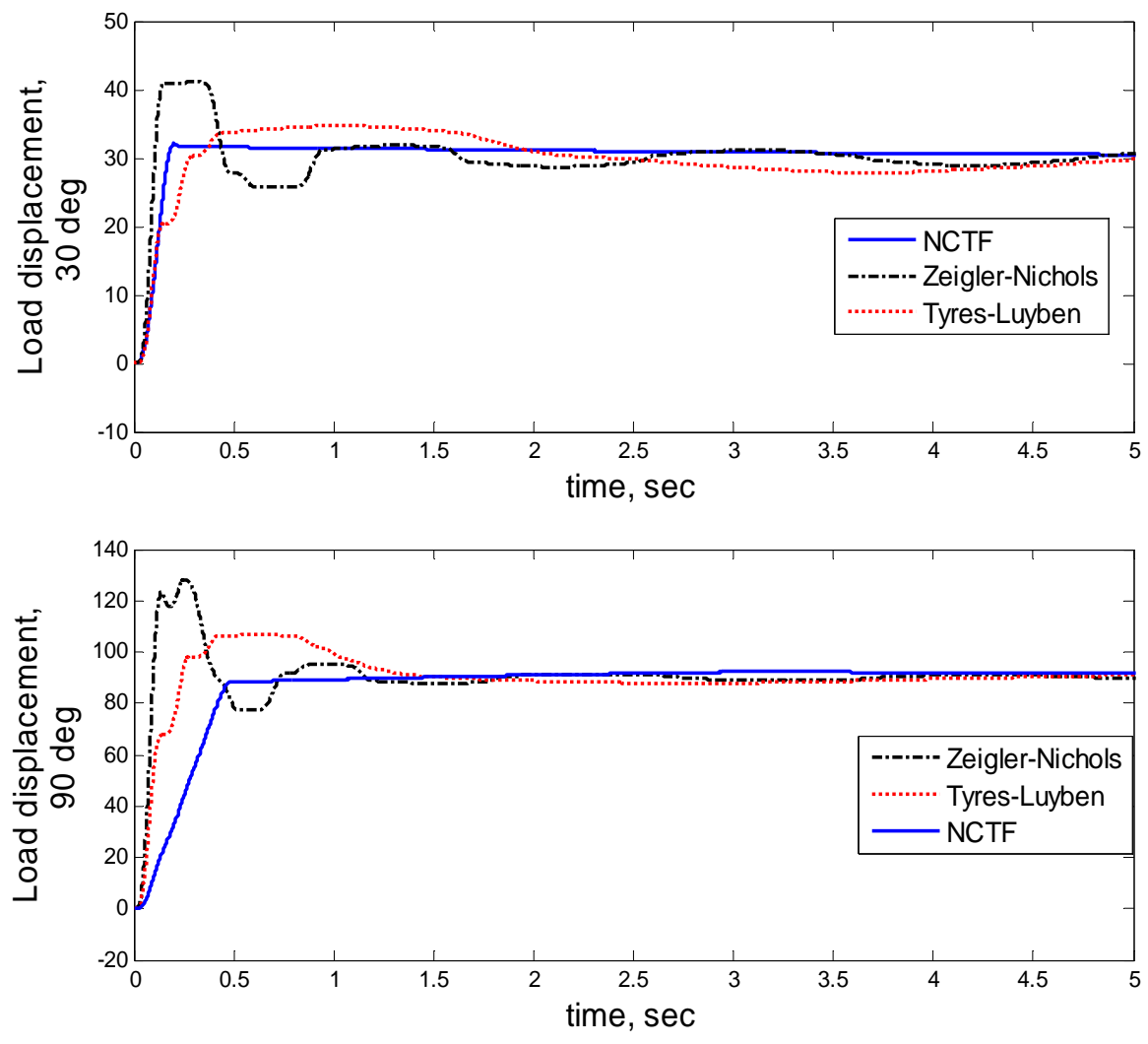

Figure 14. Step response comparison, increased friction object $\left(2 \times \tau_{t}\right)$.
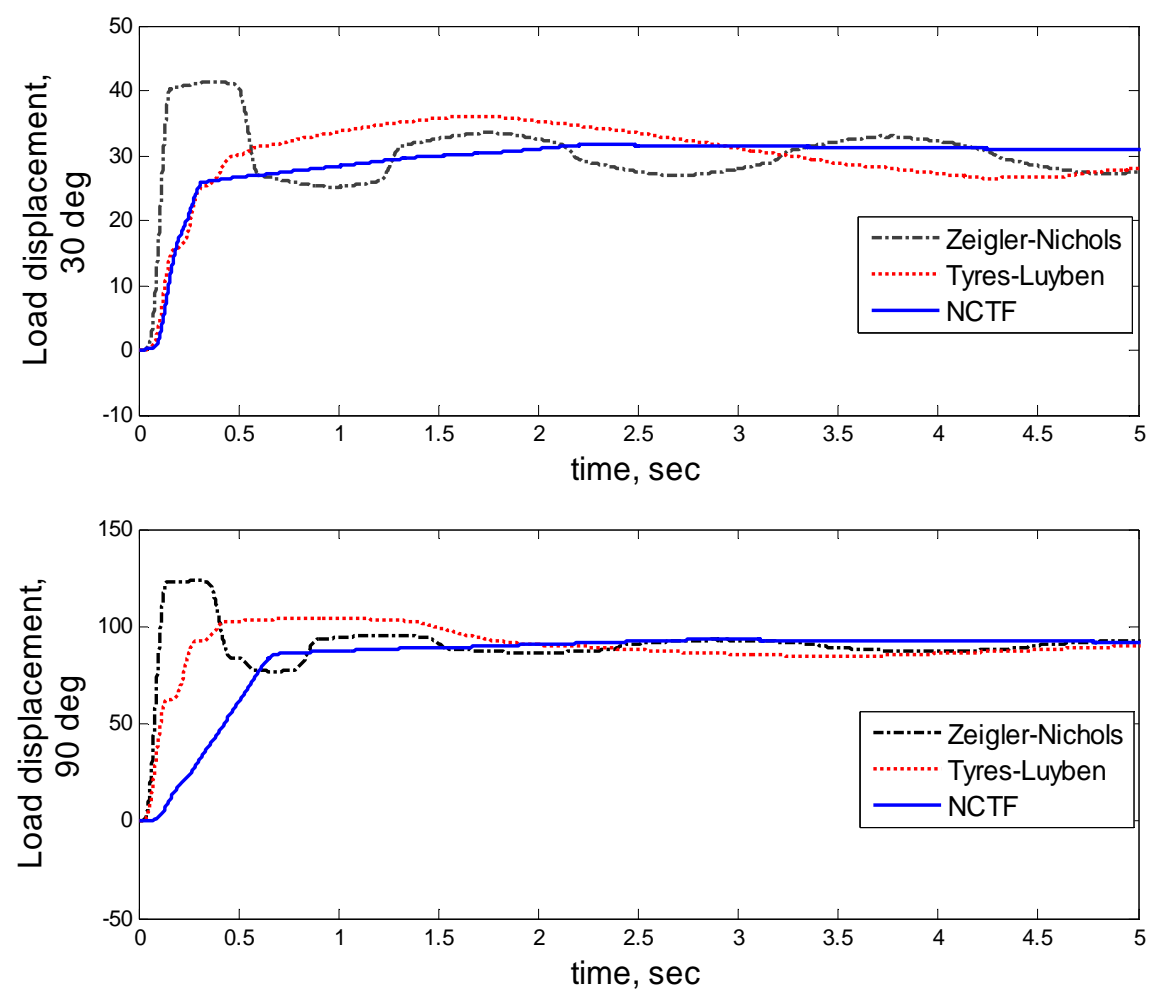

Figure 15. Step response comparison, increased friction object $\left(10 \times \tau_{t}\right)$. 

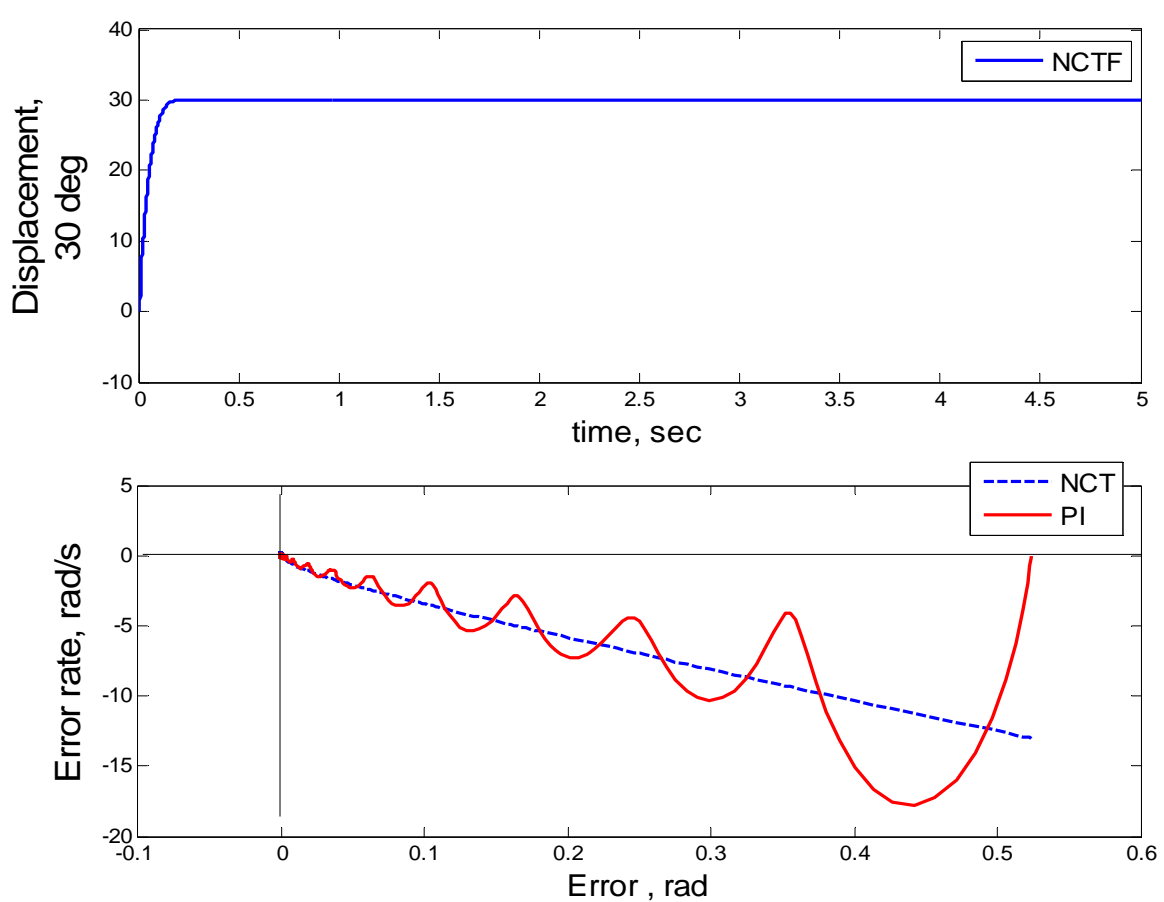

Figure 16. Object motion for 30 deg step input.

Table 5. Positioning performance comparison, increase friction object.

\begin{tabular}{cccccc}
\hline & Controller & & $\begin{array}{c}\text { Overshoot } \\
(\%)\end{array}$ & $\begin{array}{c}\text { Settling time } \\
(\mathrm{sec})\end{array}$ & $\begin{array}{c}\text { Ess } \\
(\mathrm{deg})\end{array}$ \\
\hline \multirow{4}{*}{$2 \times \mathrm{ft}$} & 30 & $\mathrm{Z}-\mathrm{N}$ & 36. & 2.505 & 2.01 \\
& deg & $\mathrm{T}-\mathrm{L}$ & 15.7 & 2.054 & 0.01 \\
& input & NCTF & 6.8 & 1.642 & 0.05 \\
& 90 & $\mathrm{Z}-\mathrm{N}$ & 42.1 & 1.763 & 2.16 \\
& deg & $\mathrm{T}-\mathrm{L}$ & 18.4 & 1.315 & 0.01 \\
& input & NCTF & 2.53 & 0.489 & 0.42 \\
& 30 & Z-N & 38 & 8.908 & 4.65 \\
& deg & T-L & 20.1 & 6.482 & 0.04 \\
& input & NCTF & 5.2 & 5.216 & 0.14 \\
& 90 & Z-N & 36.9 & 8.773 & 5.85 \\
& deg & T-L & 16 & 6.6 & 0.01 \\
& input & NCTF & 3.5 & 5.193 & 0.66 \\
\hline
\end{tabular}

\section{Conclusions}

The improvement of NCTF controller as a new practical control for two-mass positioning systems has been introduced and discussed. The improved NCTF controller consists of the NCT and the PI with notch filter compensator. The NCT is constructed using the object response data in a simple open-loop experiment and the compensator parameters are designed based on the NCT. The effectiveness of the improved NCTF controller is examined by simulation and it showed that the improved NCTF controller is much more effective and robustness then the conventional PID controller for positioning systems.

\section{Acknowledgements}

This research is supported by Ministry of Higher Educa- tion Malaysia under Vot 78606 and Malaysia-Japan International Institute of Technology (MJIIT), Universiti Teknologi Malaysia (UTM).

\section{References}

[1] B. Amstrong-Helouvry, P. Dupont and C. De Witt, "A Survey of Models, Analysis Tools and Compensation Method for the Control of Machines with Friction," Automatica, Vol. 30, No. 7, 1994, pp. 1083-1138. doi:10.1016/0005-1098(94)90209-7

[2] Wahyudi, "New Practical Control of PTP Positioning Systems," Ph.D Dissertation, Tokyo Institute of Technology Japan, Tokyo, 2002.

[3] G. E. Kollmorgen "How to work with Mechanical Resonance in Motion Control Systems," Control Engineering, Vol. 47, No. 4, 2000, p. 5. 
[4] R. L. Woods and K. L. Lawrence, "Modelling and Simulation of Dynamic Systems," Prentice Hall Inc., Upper Saddle River, 1997.

[5] Wahyudi, K. Sato and A. Shimokohbe, "Robustness Evaluation of New Practical Control Method for PTP Positioning Systems," Proceeding of 2001 IEEE/ASME International Conference on Advanced Intelligent Mechatronics, Como, 8-12 July, pp. 843-848.

[6] Wahyudi and A. Albagul, "Performance Improvement of Practical Control Method for Positioning System in the Presence of Actuator Saturation," Proceedings of 2004 IEEE International Conference on Control Applications, Taipei, 2-4 September 2004, pp. 296-302.

[7] A. V. Oppenheim and R. W. Schafer, "Discrete Time Signal Processing," Prentice Hall, Upper Saddle River, 1999.

[8] W. East and B. Lantz, "Notch Filter Design," California Institute of Technology, Technical Report LIGO-T0 50162-
00R, 29 August 2005.

[9] G. J. Maeda and K. Sato, "Practical Control Method for Ultra-Precision Positioning Using a Ballscrew Mechanism," Precision Engineering Journal, Vol. 32, No. 4, 2008, pp. 309-318. doi:10.1016/i.precisioneng.2007.10.002

[10] K. Astrom and T. Hagglund, "PID Controllers: Theory, Design and Tuning," Instrument Society of America, Durham, 1995.

[11] C. De Wit, H. Olsson, K. J. Astrom and Lischinssky, "Dynamic Friction Models and Control Design," Proceedings of American Control Conference, San Francisco, 2-4 June 1993, pp. 1920-1926.

[12] M. Y. Fitri, Wahyudi and R. Akmeliawati, "Improved NCTF Control Method for a Two Mass Point to Point Positioning System," Proceedings of the 2010 IEEE 3rd International Conference on Intelligent and Advanced systems, Kuala Lumpur, 15-17 June 2010, pp. 1-6. 